\title{
(C) \\ Timed motor function tests capacity in healthy children
} OPEN ACCESS

\author{
Aline Chacon Pereira, Márcia Gonçalves Ribeiro, \\ Alexandra Prufer de Queiroz Campos Araújo
}

Paediatrics Department, Federal University of Rio de Janeiro, Rio de Janeiro, Brazil

\section{Correspondence to} Professor Aline Chacon Pereira, Paediatrics Department, Federal University of Rio de Janeiro, Rua Bruno Lobo, No 50-3 Andar, Illha do FundãoCidade Universitária, Rio de Janeiro, RJ Cep 21941-912, Brazil; alinechacon@uol.com.br

Received 11 December 2014 Revised 12 September 2015 Accepted 22 September 2015 Published Online First 13 November 2015

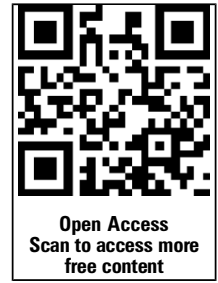

CrossMark

To cite: Pereira $A C$, Ribeiro MG, Araújo AP de QC. Arch Dis Child 2016:101:147-151.

\section{ABSTRACT}

Objective Motor function tests are used clinically and in research in children, particularly in those with neuromuscular disorders. Timed function tests are recommended in the follow-up of patients with neuromuscular disorders. This study was designed to know how healthy children perform on simple timed motor function tests.

Material and methods In a cross-sectional observational study, 345 children aged 2-12 years, followed at the Federal University of Rio de Janeiro's Institute of Paediatric, were evaluated. To be eligible they had to have acquired independent walking before the age of 14 months, be able to cope and willing to participate in the study. Anthropometric and vital signs were verified, as well as contact with smokers. The following timed motor function tests were measured: time to rise from the floor (TRF), time to walk 10 meters (10MWT) and time to run 10 meters (10MRT).

Results Improvement in time to perform those motor functions was found to occur in healthy preschool children. Stabilisation of mean times for those motor functions was seen thereafter: TRF of $1.2 \mathrm{~s}$, 10MWT of $10 \mathrm{~s}$ and 10MRT of $5 \mathrm{~s}$.

Conclusions Walking and rising speed improve with age in preschoolers, as expected, and is shown to occur up to a plateau level. Our findings for the 10MWT, 10MRT and TRF are in line with those published in 2008 for the 6 minute walk test (6MWT). The motor functions used in the present study require less time and space than the ones in the 6MWT. They should be considered more universally applicable. Those tests could be used in childcare clinics as a screening for motor disorders such as the neuromuscular diseases.

Trial registration number 1.098.302.

\section{INTRODUCTION}

Motor function tests are used clinically and in research in children with neuromuscular diseases among other health problems. Those tests determine the progression of the disease in the individual patient and guide the best treatment approach on the follow-up of the disease. Regarding research, those measures help us to understand the natural history of the neuromuscular disorders and are used as end points in clinical trials. ${ }^{1-8}$

Standardised timed function tests are available, and the most used ones in the neuromuscular diseases are time to walk 10 meters (10MWT) or time to run 10 meters (10MRT), 6 minute walk test (6MWT), time to rise from the floor (TRF), time to rise from a chair and time to climb four stairs. 69 There are two of the aforementioned timed function tests that measure walking velocity, the

\section{What is already known on this topic}

Standardised time to perform motor functions following measures is recommended for patients with neuromuscular diseases.

- There are studies evaluating the 6 minute walking test (6MWT) in healthy children.

- No normal values have been published for the more easy timed motor function tests as the time to walk 10 meters (10MWT), time to run 10 meters (10MRT) and time to rise from the floor (TRF).

\section{What this study adds}

- We observed that in normal children the maximum motor capacity is reached at the age of 6 years with subsequent stabilisation until adolescence.

- All timed motor function tests show improvement over the years in healthy preschool children.

- The simple motor tests might be useful as a motor evaluation tool for development deviations.

10MWT and the 6MWT. Of these, the last one is of more research relevance while the first one is of more clinical relevance.

There are studies evaluating the 6MWT in healthy children. ${ }^{7}{ }^{10}$ Nevertheless, the $6 \mathrm{MWT}$ is more time consuming and needs a large corridor, with $>25 \mathrm{~m}$, than the 10MWT, 10MRT and the TRF. However, no normal values have been published for those three motor tests. ${ }^{1} 35$ 11-14

Our aim is to measure how healthy children perform on the simple timed motor function tests, TRF, 10MWT and 10MRT.

\section{PATIENTS AND METHODS}

From July 2011 to July 2012, a cross-sectional observational study was undertaken at the child health outpatient clinics of the Institute of Paediatrics from the Federal University of Rio de Janeiro to measure the capacity on timed motor function tests in children from 2 to 12 years of age. Those children come to have their health monitored and for prevention of common childhood disorders. This is a Paediatric Unit with open access 
for children from the city of Rio de Janeiro. On the same day of their visit to this unit they were invited for the present study.

Eligibility criteria were age 2-12 years, normal motor independent walking development having achieved this ability by the age of 14 months, without any orthopaedic, pulmonary, cardiac or other chronic disorder, with no cognitive impairment and willing to participate in the study.

A total of 350 children participated in this study, and the final sample had 345 children (figure 1). We excluded two for being unable to perform the timed motor tests (aged 2 years old) and the rest because they were already 13 years old. The choice to include 2 year olds in the study was due to the possibility of testing children whose motor ability was the most recent acquisition.

An attending room of the child health clinic with a $15 \mathrm{~m}$ corridor with a marked $10 \mathrm{~m}$ course was used for the motor tests. All the children were tested by one of the authors (PAC) with the help of medical school students enrolled in the scientific programme (responsible for the notes and the demonstration to the children).

Gender was noted clinically. Height $(\mathrm{cm})$ and weight $(\mathrm{kg})$ measured, body mass index (BMI) was calculated and classified according WHO 2006 and 2007 references for their status (Z-score). Children were classified into BMI groups 'healthy weight' (eutrophic), 'overweight' and 'obese'. ${ }^{15}$ Vital signs and arterial blood pressure were measured before the motor tests, with patient lying and relaxed, on the left arm with the appropriate cuff (occupying 2/3 of the arm) and classified as normal ( $\leq$ P95 for child's age, gender and height) or abnormal ( $>$ P95 for child's age, gender and height). ${ }^{16} 17$ The second measurement was taken in another visit. Also, smoking habits of those living in the same house as the child were recorded because children are the most susceptible for harmful effects of passive smoke exposure and this could have an influence on functional abilities, as described in the $6 \mathrm{MWT}^{18}$ (table 1).

The timed motor function tests were explained to the children and their parents by one of the authors (ACP) and demonstrated by the medical students. All tests were done with barefoot children wearing light clothes in a calm environment under $22-26^{\circ} \mathrm{C}$. Simple stimulating verbal commands were used during the tests. For instance, "Go!", "Go on!" and "Go ahead!". Children received the explanation for each test in advance, as well as the commands that would be given.

When a misunderstanding occurred, the test was repeated up to three times and the best performance then registered. Children $<5$ years of age have difficulty understanding the motor tests and are less cooperative. As mentioned, only two

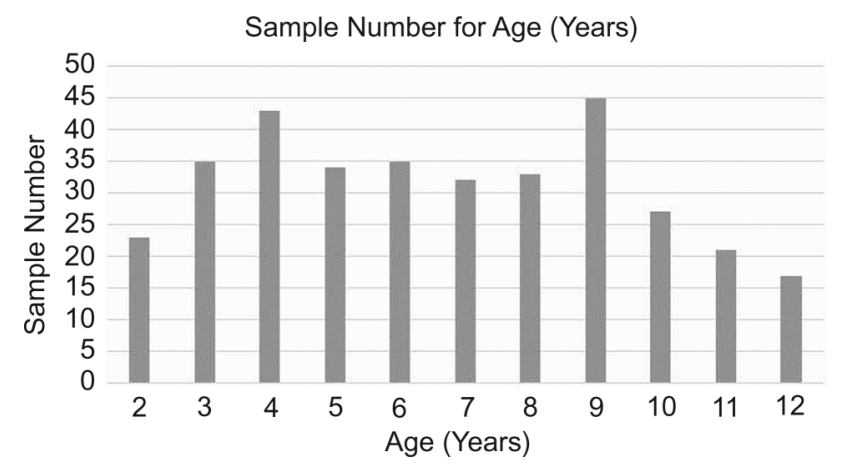

Figure 1 Sample number of age 2 years $=2$ years to 2 years and 11 months, and the same interval for the other ages.
Table 1 Sample features for age, gender, family smoking habits and anthropometry

\begin{tabular}{llcc}
\hline Feature & Variables & Sample number & Percentage \\
\hline Gender & & & \\
& Female & 177 & 51.3 \\
Family smoking habits & 168 & 48.7 \\
& Passive & & \\
& Absent & 248 & 28.4 \\
Anthropometry & & & 71.6 \\
& Eutrophic & 194 & \\
& Overweight & 78 & 56.2 \\
& Obesity & 73 & 22.5 \\
Age (years) & & & 21.3 \\
& 2 & 23 & \\
& 3 & 35 & 6.7 \\
& 4 & 43 & 10.1 \\
& 5 & 34 & 12.5 \\
& 6 & 35 & 9.9 \\
& 7 & 32 & 10.1 \\
& 8 & 33 & 9.3 \\
& 9 & 45 & 9.6 \\
& 0 & 27 & 13.0 \\
& 11 & 21 & 7.8 \\
& 12 & 17 & 6.1 \\
& & & 4.9 \\
\hline
\end{tabular}

children did not perform all tests and were therefore excluded from the study. Another six children (age 2-5) performed two out of three tests, and their obtained measures were considered in the results. The description of the motor tests follows:

1. TRF: The time in seconds taken to stand up from seated on floor to a straight standing position without help.

2. The children were placed in a seated position with their legs flexed and arms on their side. On the command "One, two, three and Go" the child should start, as well as the stopwatch, when saying "Go". The timer was stopped when the children assumed an upright position with their arms by their side.

3. 10MWT: The time in seconds for the child to walk barefoot and without any help the marked distance of $10 \mathrm{~m}$. This should be done in a normal pacing walking (like walking in a shopping mall). The stopwatch was pressed when saying "Go". Continuously encouraged the children until they crossed the finish line and stopped the timer when the second foot came across the finish line.

4. 10MRT: The same as above but as fast as possible (running as if the child were after a ball). Started the stopwatch when saying "Go". Continuously encouraged the children until they crossed the finish line and stopped the timer when the second foot came across the finish line.

5. In all timed tests, a stopwatch was used and measurements recorded to $1 / 100$ th of a second. Data were stored on formularies and inserted on electronic file (Microsoft Office Excel V.2007) right after collection. Data were analysed for mean values with SD and presented in tables and graphs. Since the dispersion graph had a normal presentation, $t$ test was used for statistical analyses (significant if $<0.05$ ) comparing for gender, family smoking habits (yes or no) and obesity (obese and not obese). 
Table 2 Mean time of motor function tests according to age

\begin{tabular}{|c|c|c|c|c|c|c|c|c|c|c|c|}
\hline \multirow[b]{2}{*}{ Motor tests (s) } & \multicolumn{11}{|c|}{ Age (years) } \\
\hline & 2 & 3 & 4 & 5 & 6 & 7 & 8 & 9 & 10 & 11 & 12 \\
\hline \multicolumn{12}{|l|}{$T R F$} \\
\hline Maximum & 2.32 & 2.57 & 2.78 & 1.54 & 1.87 & 1.53 & 2.03 & 1.74 & 1.8 & 1.52 & 1.77 \\
\hline Minimum & 1.05 & 0.69 & 0.8 & 0.72 & 0.47 & 0.83 & 0.71 & 0.82 & 0.74 & 0.62 & 0.81 \\
\hline Mean & 1.7 & 1.63 & 1.79 & 1.13 & 1.17 & 1.18 & 1.37 & 1.28 & 1.27 & 1.07 & 1.29 \\
\hline SD & 0.62 & 0.94 & 0.99 & 0.41 & 0.7 & 0.35 & 0.66 & 0.46 & 0.53 & 0.45 & 0.48 \\
\hline \multicolumn{12}{|l|}{$10 M W T$} \\
\hline Maximum & 15.2 & 13.91 & 13.46 & 12.12 & 12.47 & 11.9 & 11.79 & 12.03 & 12.35 & 10.83 & 11.05 \\
\hline Minimum & 11.08 & 10.19 & 8.68 & 8.58 & 7.75 & 7.8 & 8.11 & 7.79 & 8.63 & 7.81 & 7.79 \\
\hline Mean & 13.14 & 12.05 & 11.07 & 10.35 & 10.11 & 9.85 & 9.95 & 9.91 & 10.49 & 9.32 & 9.42 \\
\hline SD & 2.06 & 1.86 & 2.39 & 1.77 & 2.36 & 2.05 & 1.84 & 2.12 & 1.86 & 1.51 & 1.63 \\
\hline \multicolumn{12}{|l|}{$10 M R T$} \\
\hline Maximum & 9.43 & 7.99 & 7.38 & 6.3 & 5.63 & 5.47 & 5.53 & 5.48 & 5.39 & 5.44 & 5.6 \\
\hline Minimum & 6.47 & 5.79 & 4.98 & 4.46 & 4.35 & 4.25 & 4.23 & 4.08 & 4.05 & 3.82 & 4.18 \\
\hline Mean & 7.95 & 6.89 & 6.18 & 5.38 & 4.99 & 4.86 & 4.88 & 4.78 & 4.72 & 4.63 & 4.89 \\
\hline SD & 1.48 & 1.1 & 1.2 & 0.92 & 0.64 & 0.61 & 0.65 & 0.7 & 0.67 & 0.81 & 0.71 \\
\hline BMI (mean) & 16.28 & 16.68 & 17.33 & 16.52 & 16.78 & 17.43 & 17.96 & 18.82 & 19.53 & 18.68 & 20.14 \\
\hline SD & 1.70 & 1.75 & 2.69 & 2.07 & 2.19 & 2.33 & 2.71 & 3.45 & 2.93 & 2.58 & 3.50 \\
\hline
\end{tabular}

10MRT, time to run 10 meters; 10MWT, time to walk 10 meters; BMI, body mass index; TRF, time to rise from the floor.

\section{RESULTS}

A total of 345 healthy children, almost equally represent by gender $(51.3 \%$ of females) aged $2-12$ years, had their motor capacity measured using the 10MWT, 10MRT and TRF. Most of them were of normal weight $(56.2 \%)$, but some were overweight $(22.5 \%)$ and obese $(21.3 \%)$. Most came from homes free of tobacco $(71.6 \%)$. Sixteen children had a first arterial blood pressure measure above the 95 th centile for age, gender and height. Nonetheless, on a second measure during another routine child health care visit, eight had a normal second measure.

The mean time for each of the motor function tests, according to each age, is shown in table 2. Figures 2-4 show the evolution of the capacity.

The TRF declines up to the age of 5 years and remains below $1.5 \mathrm{~s}$ from there on (figure 2).

The 10MWT also decreases with age, from $13 \mathrm{~s}$ to 10 or below after the age of 6 years (figure 3 ).

The 10MRT also decreases with age to below $5 \mathrm{~s}$ after the age of 6 years (figure 4 ).

T test was applied to evaluate the independent variables. As a whole, no significant difference was found among gender in general. However, boys tend to have a better capacity in the older age groups. Only for those aged 7, 10 and 11 years a statistical significant value has been found $(p=0.032,0.011$ and 0.006, respectively). For obese children (Z-score $>+3$ ), 10MWT and 10MRT did not differ significantly, but the TRF was significantly lower in this subgroup $(p=0.0024)$. Finally, no significant difference was found in those tests whether there were tobacco users in the children's home or not.

\section{DISCUSSION}

The present study has shown that healthy children from the age of 2 years reduce the time taken to perform motor function tests until they reach a plateau at the age of 6 years. This finding does agree with what should be expected regarding motor development.

Variability as shown by SD is in general similar among age groups for TRF (except for 3 and 4 year olds), and 10MWT. As for 10MRT, there is a less variability from age 2 to 5 . This might be explained by better motor capacity or better comprehension.

The variability as shown in table 2 by SD on each age for each test shows that only in 10MRT does a clear decrement on variability occur before the age of 6 years. Lifting from the floor is the function test most related to pelvic girdle motor strength,

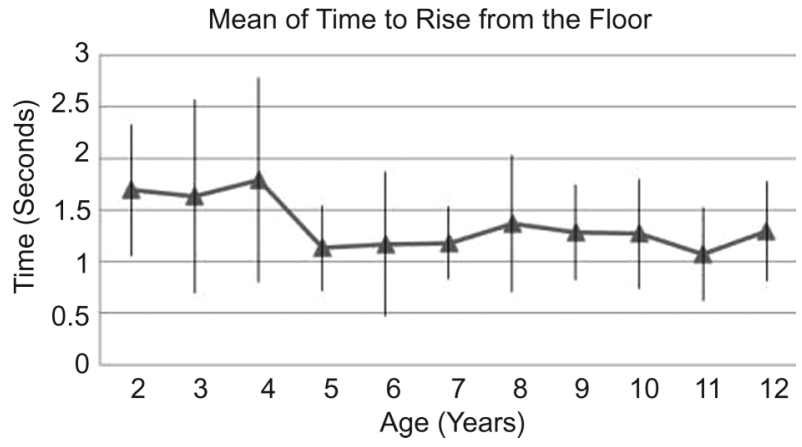

Figure 2 Mean of time to rise from the floor and SD.

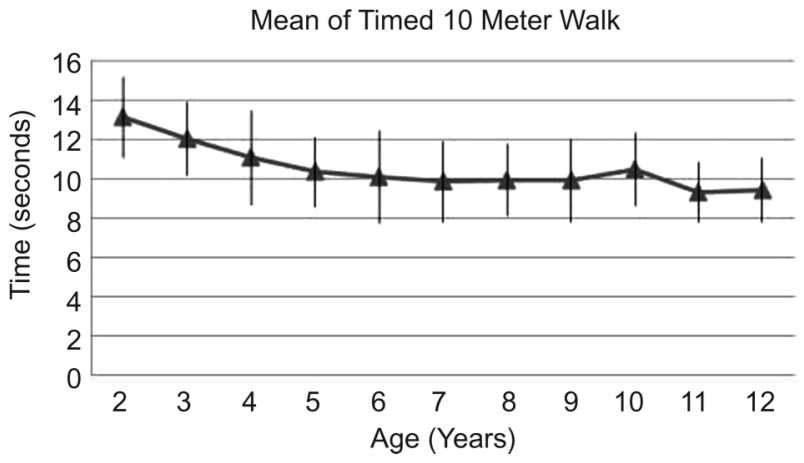

Figure 3 Mean time to walk 10 meters and SD. 


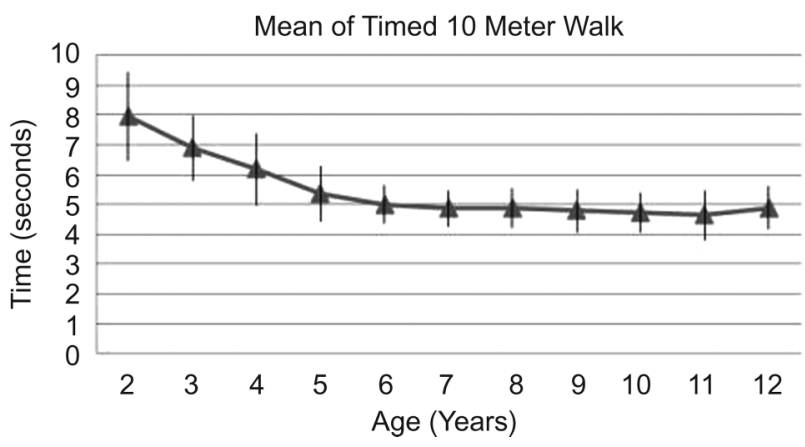

Figure 4 Mean time to run 10 meters and SD.

and this test does not show greater SD before the age of 6 years. Running requires not only greater strength but also better collaboration. Therefore, for the 10MRT both motor development and collaboration can explain our findings.

Our findings for the 10MWT, 10MRT and TRF are in line with those published in 2008 for the $6 \mathrm{MWT}^{13}$ For children aged 4-11 years, the 6MWT reached a plateau at the age of 7 after a gradual increase of the distance walked from the age 4-6 years in this test. Therefore, they had a better capacity, as also shown in our sample up to the age of 6 on 10MWT, 10MRT and TRF. Thus, those objective motor tests show similar behaviour regarding the developmental aspect. Since the 10MWT, 10MRT and TRF require less time and space, they also are less influenced to motivational aspects and should be considered more universally applicable.

In our study, the 10MRT had the least variability (SD 0.611.48) for the whole sample regardless of the age. In comparison to the 10MWT, a greater homogeneity for running could be explained because of maximal motor function requirement in this task. Step distance and speed can vary on walking, more than on running, and this could justify more variability on 10MWT than on 10MRT.

As for the TRF the very short timespan for this test could be responsible for the greater variability observed, particularly for the preschool children. The accuracy of the manual chronometer may be a limiting factor. To analyse the influence of time measure, a photoelectric equipment could be used in future studies comparing the times with that of a manual chronometer.

The peak motor capacity in the present timed motor function tests reflects what is already known for the general motor development. Gross motor function is already achieved in early preschool age, but all general motor tasks are better performed with age. Kakebeeke and collaborators, in 2013, studied the hopping ability of children. The children aged 3 years were unable to hop more than three times on one leg, but those $>5$ years were able to do it. ${ }^{19}$

On timed tests, Denckla in 1973 and 1994 had shown that speed of tasks was slower in younger children and gradually improved up to the age of $8-10$ years of age. There are agespecific fine motor abilities, as the ones found for repetitive, alternating, sequenced movements. ${ }^{20}$

We have found that the mean time for the motor function tests from the age of 6 years remained stable up to the age of 12 and their values were as follows: TRF of $1.2 \mathrm{~s}, 10 \mathrm{MWT}$ of $10 \mathrm{~s}$ and 10MRT of $5 \mathrm{~s}$. As such, those times could be a reference for the motor development evaluation and for the follow-up of children with neuromuscular disease as the two most common of them, Duchenne muscular dystrophy and spinal muscular atrophy. In these two progressive disorders, natural history studies show that children's capacity in the motor function tests gets worse over time. ${ }^{21}$ Treatment modalities can be followed better with objective measures and those function tests have been main end points in the research in current clinical studies. There is also a possibility that those tests might in the early stage of those diseases show a difference that could help the clinicians and other health professions to screen for children with motor development deviations. Those three tests are easy to undertake and require less resources and space compared with the $6 \mathrm{MWT}$. Furthermore, although the ability to rise from the floor is usually lost sooner than that to ambulate in neuromuscular diseases, the ability to walk $10 \mathrm{~m}$ is expected to be lost later than that to walk for $6 \mathrm{~min}$. The $6 \mathrm{MWT}$ measured the distance a patient can walk over a 6 min period, usually including cardiac and pulmonary measurement. Used for prognosis, diagnosis and response to therapy, this motor test is more difficult to be concluded in neuromuscular disease patients. When neuromuscular patients lose their walking ability, all those tests cannot be used and should be changed to measure of other functions. Nevertheless, it is probable that losing the ability to walk during 6 min should be lost before the ability to walk $10 \mathrm{~m}$.

Our sample, a hospital-based one, but within from a healthy group of children attending the outpatient department, showed that preschool children seem not to have a difference in motor capacity when gender is compared; obese children tend to have a worse capacity; and family members' smoking habits seem not to affect test results. It is important to mention that this study was not designed to prove or not differences on those variables, which were only explored in the present study for their theoretical or shown influence in other motor function tests.

A gender difference in motor capacity can be expected in older children, as it is as well in longer motor tests. ${ }^{20} 22$ We only found a significant difference in the 10MRT above the age of 7 years, with shorter time for the boys. The male hormones are known to influence muscle mass and height; this effect is apparent as puberty approaches. ${ }^{20}$ Others, although using the 6MWT, did not find a difference in gender in younger age groups either. ${ }^{17}$

In our sample, we had $43.8 \%$ overweight and obese children (22.5\% of overweight and $21.3 \%$ of obese); this distribution reflects recent national survey findings for weight classification. In 2008-2009, excess weight reached 33.5\% (males 34.8\% and females $32 \%$ ) and obesity reached $14.2 \%$ (males $16.6 \%$ and females $11.8 \%$ ) of children aged 5-9 years of the Brazilian population (Brazilian Institute of Geography and Statistics). Excess weight is associated with less motivation to participate in active motor tasks. ${ }^{24}$ Weight is a variable related to final distance and walking speed on the 6MWT. ${ }^{1022} 24$ Only a slight significance was found in our sample when comparing the capacity on the 10MWT in normal weight group with those with Z-score $>$ $+1(p=0.046)$ or those with Z-score $>+2(p=0.027)$. We had only a small number of children with a Z-score $>3$ (11), and in those no significant difference was found $(p=0.47)$. Therefore, we suggest that weight influence in this motor test should be further studied in the future.

In our sample, exposure to tobacco did not affect the motor function tests. Tobacco exposure from one or both parents has been shown to have a negative influence on the 6MWT result. ${ }^{18} 25$ We did not find any difference in our sample. Lack of tobacco exposure influence on these timed tests might be explained because they are shorter than the 6MWT. There are no previous studies investigating this issue. We did not take into account the load of tobacco exposure, number of daily exposure hours and if in a closed or an open window environment. 


\section{CONCLUSION}

In healthy children, a faster capacity in timed motor tests is found from the age of 2 to the age of 6 years with subsequent stabilisation during the following years up to the age of 12 . This probably reflects normal development.

The 10MWT, 10MRT and TRF used in the present study are quick motor function tests (take from 2 to $10 \mathrm{~s}$ ), and this may be a reason for very little or no influence of gender, weight and tobacco exposure. Those tests could be used in future studies to measure their sensibility and specificity to evaluate them as screening tool for motor disorders such as the neuromuscular diseases.

Twitter Follow Aline Pereira at @Aline Chacon

Acknowledgements Thanks to the children and their parents for the participation in this study, and to the medical school students for their help with data registration.

Collaborators Non-author contributors: Lapido, Ana Laura Marques Barta, Pacheco, Brian Sossai, Orlandi, Clara Vasconcelos, Tostes, Isabel Sampaio, Araujo, Igor Prufer de Queiroz Campos, Geraldino, Ana Clara da Costa, Borges, Bruno Martins de Novaes, Moura, Deborah Cheble, Garritano, João Gabriel Garcia, Jordão, Paula Moskovicsmedical school students. All non-authors are medical students and contributed in demonstration of the motor tests for children as well as to the analysis of data.

Contributors All authors contributed to the acquisition, analysis and interpretation of data; drafting the work; final approval of the version to be published and agreements for all aspects of the manuscript.

Funding Research grant FAPERJ of Araújo, APQC.

Competing interests None declared.

Patient consent Obtained.

Ethics approval The Research and Ethics Committees of the Institute of Pediatrics Martagão Gesteira (IPPMG) at Rio de Janeiro, Brazil.

Provenance and peer review Not commissioned; externally peer reviewed.

Open Access This is an Open Access article distributed in accordance with the Creative Commons Attribution Non Commercial (CC BY-NC 4.0) license, which permits others to distribute, remix, adapt, build upon this work non-commercially, and license their derivative works on different terms, provided the original work is properly cited and the use is non-commercial. See: http://creativecommons.org/ licenses/by-nc/4.0

\section{REFERENCES}

1 Mazzone E, Martinelli D, Berardinelli A, et al. North Star Ambulatory Assessment, 6-minute walk test and timed items in ambulant boys with Duchenne muscular dystrophy. Neuromuscul Disord 2010;20:712-16.

2 Vandervelde L, Van den Bergh PYK, Renders A, et al. Relationships between motor impairments and activity limitations in patients with neuromuscular disorders. I Neurol Neurosurg Psychiatry 2009;80:326-32.

3 Graham JE, Ostir GV, Kuo YF, et al. Relationship between test methodology and mean velocity in timed walk tests: a review. Arch Phys Med Rehabil 2008;89:865-72.
4 Wokke JH, Escolar DM, Pestronk A, et al. Clinical features of late-onset Pompe disease: a prospective cohort study. Muscle Nerve 2008;38:1236-45.

5 Vos-Vromans DCWM, de Bie RA, Erdmann PG, et al. The responsiveness of the Ten-Meter Walking Test and other measures in patients with hemiparesis in the acute phase. Physiother Theoria Pract 2005;21:173-80.

6 Brooke MH, Griggs RC, Mendell JR, et al. Clinical trial in Duchenne dystrophy. 1. The design of the protocol. Muscle Nerve 1981;4:186-97.

7 Wang $\mathrm{CH}$, Finkel RS, Bertini ES, et al. Consensus statement for standard of care in spinal muscular atrophy. J Child Neurol 2007;22:1027-49.

8 Bushby K, Finkel R, Birnkrant DJ, et al. Diagnosis and management of Duchenne muscular dystrophy, part 1: diagnosis, and pharmacological and psychosocial management. Lancet Neurol 2010;9:77-93.

9 Florence JM, Pandya S, King WM, et al. Clinical trials in Duchenne dystrophy. Standardization and reliability of evaluation procedures. Phys Ther 1984;64:41-5.

10 Yared A. Clinical aspects of hypertension in children. J Med Liban 2010;58:127-31

11 McDonald CM, Henricson EK, Han JJ, et al. The 6-minute walk test as a new outcome measure in Duchenne muscular dystrophy. Muscle Nerve 2009:41:500-10

12 Kierkegaard $M$, Tollbäck $A$. Reliability and feasibility of the six minute walk test in subjects with myotonic dystrophy. Neuromuscul Disord 2007;17:94-9.

13 Lammers AE, Hislop AA, Flynn Y, et al. The 6-minute walk test: normal values for children of 4-11 years of age. Arch Dis Child 2008;93:464-8.

14 ATS Committee on Proficiency Standards for Clinical Pulmonary Function Laboratories. ATS statement: guidelines for the six_minute walk test. Am J Respir Crit Care Med 2002;166:111-17.

15 Vasconcelos AB, Fagundes A, Nilson EA, et al. Guidelines for collection and analysis of anthropometric data in health services: technical standard system of food and nutrition surveillance - SISVAN 2011.

16 Bonvin A, Barral J, Kakebeeke TH, et al. Weight status and gender-related differences in motor skills and in child care-based physical activity in young children. BMC Pediatr 2012;12:23.

17 Enright PL. The Six-Minute Walk Test. Respiratory Care 2003;48:783-5.

18 Pavić I, Pavić P, Palcić I, et al. Influence of passive smoking on functional abilities in children. Int J Environ Health Res 2012:22:355-61.

19 Kakebeeke TH, Caflisch J, Chaouch A, et al. Neuromotor development in children. Part 3: motor performance in 3 to 5 years old. Dev Med Child Neurol 2013;55:248-56

20 Largo RH, Fischer JE, Rousson V. Neuromotor development from kindergarten age to adolescence: developmental course and variability. Swiss Med Wkly 2003;133:193-9.

21 McDonald CM, Henricson EK, Abresch RT, et al. The 6-minute walk test and other endpoints in Duchenne muscular dystrophy: longitudinal natural history observations over 48 weeks from a multicenter study. Muscle Nerve 2013;48:343-56.

22 Goemans N, Klingels $\mathrm{K}$, van den Hauwe $\mathrm{M}$, et al. Test-retest reliability and developmental evolution of the 6-min walk test in Caucasian boys aged 5-12 years. Neuromuscul Disord 2013:23:19-24.

23 Li AM, Yin J, Yu CCW, et al. The six-minute walk test in healthy children: reliability and validity. Eur Respir J 2005:25:1057-60.

24 Fong SSM, Lee VYL, Chan NNC, et al. Motor ability and weight status are determinants of out-of-school activity participation for children with developmental coordination disorder. Res Dev Disabil 2011:32:2614-23.

25 Cheraghi M, Salvi S. Environmental tobacco smoke (ETS) and respiratory health in children. Eur J Pediatr 2009:168:897-905. 